\title{
Cannabinoid Receptor-Mediated Regulation of Neuronal Activity and Signaling in Glomeruli of the Main Olfactory Bulb
}

\author{
Ze-Jun Wang, Liqin Sun, and Thomas Heinbockel \\ Department of Anatomy, Howard University College of Medicine, Washington, DC 20059
}

Cannabinoid receptors (CB1Rs) are present in glomeruli of the main olfactory bulb. The functions of CB1Rs and their endogenous activators, endocannabinoids, for glomerular signaling are unknown. Glomeruli contain at least three types of neurons: periglomerular (PG), external tufted (ET), and short-axon (SA) cells. PG cells form inhibitory GABAergic dendrodendritic synapses with ET cells. ET cells form excitatory glutamatergic dendrodendritic synapses with PG and SA cells. In mouse brain slices, we used whole-cell patch-clamp recordings to study the role of CB1Rs in regulating PG and ET cells. Cannabinoids displayed strong, direct inhibitory effects on PG cells and weak effects on ET cells. Single pulses or a train of pulses of depolarizing current injected into an ET cell evoked suppression of IPSCs. This suggests retrograde endocannabinoid signaling, namely, depolarization-induced suppression of inhibition (DSI) in ET cells. Our results support the hypothesis that burst firing of ET cells triggers the release of endocannabinoids which in turn directly inhibit PG cells and reduce GABA release from PG cells. This, in turn, can result in a transient reduction of PG cell inhibitory input to ET cells.

\section{Introduction}

Endocannabinoids (eCBs) were found to act as retrograde signaling molecules in the hippocampus, cerebellum, neocortex, and amygdala (for review, see Alger, 2002; Kano et al., 2009). eCBs act at $\mathrm{CB} 1 \mathrm{R}$ at presynaptic terminals to reduce transmitter release (GABA, glutamate). One type of short-term synaptic plasticity, originally observed in the cerebellum and hippocampus, is mediated by eCBs, namely DSI (depolarization-induced suppression of inhibition). In DSI, eCBs are released from depolarized principal neurons and travel to presynaptic inhibitory interneurons to transiently reduce presynaptic firing and neurotransmitter (GABA) release.

Immunohistochemical and autoradiographic studies indicate that $\mathrm{CB} 1 \mathrm{R}$ is present in the main olfactory bulb (MOB) glomerular layer (Herkenham et al., 1991; Pettit et al., 1998; Tsou et al., 1998; Moldrich and Wenger, 2000). Neurons in the glomerular layer fall into three subpopulations: periglomerular (PG), external tufted (ET), and short-axon (SA) cells (for review, see Ennis et al., 2007). PG cells are GABAergic, SA cells express both GABA and dopamine, and ET cells are glutamatergic (Hayar et al., 2004b; Kiyokage et al., 2010). PG cells receive input from the olfactory nerve or dendrodendritic glutamatergic input from ET or mitral cells (Hayar et al., 2004b; Ennis et al., 2007). PG cells contain

Received Oct. 21, 2011; revised April 19, 2012; accepted April 30, 2012.

Author contributions:Z.-J.W. and T.H. designed research; Z.-J.W., L.S., and T.H. performed research; Z.-J.W. and T.H. analyzed data; Z.-J.W. and T.H. wrote the paper.

This work was supported by the Whitehall Foundation, and USPHS Grants S06GM08016 (MBRS-SCORE, NIGMS/ $\mathrm{NIH}$ ) and 8G12MD007597 (RCMI, NIH-NIMHD).

Correspondence should be addressed to Thomas Heinbockel, Department of Anatomy, HUCM, 520 W Street, NW, Washington, DC 20059. E-mail: theinbockel@howard.edu.

DOI:10.1523/JNEUROSCI.5333-11.2012

Copyright $\odot 2012$ the authors $\quad 0270-6474 / 12 / 328475-05 \$ 15.00 / 0$
GABA and presynaptically inhibit olfactory receptor neurons through GABAergic transmission (Aroniadou-Anderjaska et al., 2000; Murphy et al., 2005). ET cells receive spontaneous bursts of IPSCs from PG cells at inhibitory GABAergic synapses (Hayar et al., 2005). Neurons in the glomerular layer are immunoreactive for enzymes that synthesize eCBs (Piomelli, 2003; Okamoto et al., 2007; Allen Institute for Brain Science, 2009). ET cells can be a potential source of eCBs.

To determine the function of the eCB system in olfactory glomeruli, we used whole-cell patch-clamp recording and tested the effects of agonists/antagonists of CB1R on cellular and network activity.

\section{Materials and Methods}

Wild-type mice of either sex (C57BL/6J, Jackson Laboratory) were used in agreement with Institutional Animal Care and Use Committee and NIH guidelines. Sixteen- to 25-d-old mice were decapitated, the MOBs dissected out, and immersed in artificial CSF (ACSF) at $4^{\circ} \mathrm{C}$, as previously described (Heinbockel et al., 2004). Horizontal slices (400 $\mu \mathrm{m}$ thick) were maintained at $30 \pm 0.5^{\circ} \mathrm{C}$ by superfusion with oxygenated ACSF.

Recording methods have been described previously (Heinbockel et al., 2004). Recording pipettes (5-8 M $\Omega$ ) were pulled on a Flaming-Brown P-97 puller (Sutter Instrument Co.) from $1.5 \mathrm{~mm}$ outer diameter borosilicate glass with filament. Data were obtained using a Multiclamp 700B amplifier (Molecular Devices) and digitized on computer disc (Clampex 10.1, Molecular Devices). Data were also collected through a Digidata 1440A Interface (Molecular Devices) and digitized at $10 \mathrm{kHz}$.

The ACSF consisted of the following (in $\mathrm{mm}$ ): $124 \mathrm{NaCl}, 3 \mathrm{KCl}, 2$ $\mathrm{CaCl}_{2}, 1.3 \mathrm{MgSO}_{4}, 10$ glucose, 4.4 sucrose, $26 \mathrm{NaHCO}_{3}, 1.25 \mathrm{NaH}_{2} \mathrm{PO}_{4}$ ( $\mathrm{pH} 7.4,300 \mathrm{mOsm}$ ), saturated with $95 \mathrm{O}_{2} / 5 \% \mathrm{CO}_{2}$. For intracellular recording of spiking activity, the pipette-filling solution consisted of the following (in mM): $144 \mathrm{~K}$-gluconate, $2 \mathrm{MgCl}_{2}, 10$ HEPES, $5 \mathrm{Mg}_{2} \mathrm{ATP}, 0.5$ $\mathrm{Na}_{3} \mathrm{GTP}, 2 \mathrm{NaCl}, 0.2$ EGTA. For IPSCs, EPSCs recording and DSI exper- 
iments, electrodes were filled with a low- $\mathrm{Cl}^{-}$or high- $\mathrm{Cl}^{-}$-based solution depending on the experiment. Low- $\mathrm{Cl}^{-}$-based pipette solution contained the following (in mM): 125 cesium methanesulfonate $\left(\mathrm{CsMeSO}_{3}\right)$, $1 \mathrm{NaCl}, 10$ phosphocreatine di-tris salt, 5 ATP, 0.5 GTP, 0.5 EGTA, 10 HEPES, 10 QX-314 [2(triethylamino)- $N$-(2,6-dimethylphenyl) bromide], pH 7.3 with $1 \mathrm{~N} \mathrm{CsOH} \mathrm{(290} \mathrm{mOsm).} \mathrm{High-} \mathrm{Cl}^{-}$-based pipette solution contained the following (in $\mathrm{mm}$ ): 110 cesium cloride, 10 tetraethylammonium-Cl, $2 \mathrm{NaCl}, 10$ phosphocreatine di-tris salt, $5 \mathrm{ATP}$, 0.5 GTP, 0.5 EGTA, 10 HEPES, 10 QX-314, pH 7.3 with $1 \mathrm{~N} \mathrm{CsOH} \mathrm{(290}$ mOsm).

ET cells were identified by their spontaneous intrinsic burst firing (see Fig. $2 \mathrm{~A}$ ) that persisted in synaptic blockers, a pear-shaped cell body located in the bottom half of the glomerular layer, an extensively ramifying apical dendrite in one glomerulus, and absence of lateral dendrites in the external plexiform layer (Hayar et al., 2004b; Liu and Shipley, 2008). PG cells were identified by their location around the glomerular neuropil and electrophysiological characteristics including membrane potential, input resistance and membrane capacity (Shao et al., 2009). SA cells were excluded from PG cells based on the fact that compared with PG cells, SA cells have relative lower input resistance, higher firing frequency and larger cell bodies (Aungst et al., 2003; Hayar et al., 2004b; Kiyokage et al., 2010). We recorded from two different PG cell subtypes that were both located at the periphery of individual glomeruli but exhibited different firing behaviors and input resistances. One subtype displayed sustained spontaneous spiking with relatively low input resistance (sPG cell), whereas the other subtype required depolarizing current to exhibit firing (nPG cells) and had relatively smaller cell bodies with higher input resistance and a more negative membrane potential. A PG cell body was relatively smaller than that of an ET cell. ET cells received spontaneous EPSCs and bursts of IPSCs from PG cells, whereas PG cells received spontaneous bursts of EPSCs (Hayar et al., 2004a,b, 2005).

The following drugs were bath applied: L-2-amino-5-phosphonopentanoic acid (AP5, APV), 6-cyano-7-nitroquinoxaline-2-3-dione (CNQX), (2-(3-carboxypropyl)-3-amino-6-(4 methoxyphenyl)-pyridazinium bromide (gabazine, SR-95531), $(R)-(+)-[2,3-d i h y d r o-5-m e t h y l-3-(4-$ morpholinylmethyl)pyrrolo[1,2,3,-de]-1,4-benzoxazin-6-yl]-1-naphthalenylmethanone mesylate (WIN55,212-2 mesylate, WIN), $N$-(piperidin-1-yl)-5-(4-iodophenyl)-1-(2,4-dichlorophenyl)-4methyl$1 \mathrm{H}$-pyrazole-3-carboxamide (AM251). Chemicals were supplied by Sigma-Aldrich and Tocris Bioscience.

Data were analyzed using Clampfit (Molecular Devices) and Mini Analysis (Synaptosoft) software. Detection of events (intracellularly recorded spontaneous (s)EPSCs and spontaneous (s)IPSCs) was performed off-line using Mini Analysis program. We quantified the averaged integral area which is an indication of both frequency and amplitude of sIPSCs. We calculated the integral area of individual sIPSCs within $1.3 \mathrm{~s}$ to determine total synaptic area $(A=$ number of events for $1.3 \mathrm{~s} \times$ mean area of sIPSCs). The calculation of DSI was slightly modified as follows: DSI $(\%)=100 \times\left[A_{\text {post }} / A_{\text {pre }}\right]$ (Fortin et al., 2004). $A_{\text {post }}$ is the total area of $1.3 \mathrm{~s}$ sIPSCs after depolarization. $A_{\text {pre }}$, the total area of $1.3 \mathrm{~s}$ sIPSCs before depolarization, was obtained by measuring the total area of three continuous $1.3 \mathrm{~s}$ sIPSCs before depolarization and averaging the value. Membrane potentials were calculated from the steady-state membrane potential that occurred after a single action potential. Minimal membrane potential was measured as membrane potential for burst firing (Liu and Shipley, 2008). Numerical data were expressed as the mean \pm SEM. Tests for statistical significance $(p<0.05)$ were performed using paired Student's $t$ test, and nonparametric Wilcoxon signed rank test for paired data of small sample sizes $(\sim 5)$, or one-way ANOVA followed by the Bonferroni test for multiple comparisons.

\section{Results}

\section{Regulation of periglomerular cell activity through CB1R}

PG cells are likely candidates for direct effects of eCBs since CB1R is robustly expressed in the glomerular layer (Moldrich and Wenger, 2000). PG cells are neurochemically and functionally heterogeneous (Ennis et al., 2007; Shao et al., 2009; Kiyokage et al., 2010). Recordings were obtained from 49 sPG cells and 12
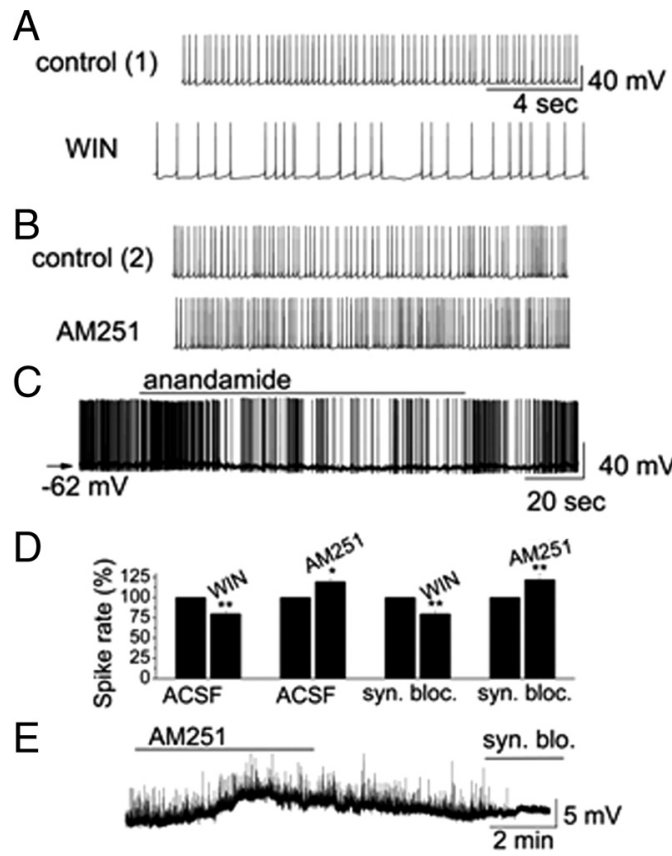

Figure 1. CB1R regulated the activity of periglomerular cells. $A, B$, Original recordings illustrate that CB1R agonist WIN reduced the firing rate of an SPG cell. CB1R antagonist AM251 increased spiking of an SPG cell. Recordings for WIN and AM251 are from the same SPG cell. $C$, Anandamide reduced firing and hyperpolarized membrane potential in an $\mathrm{PPG}$ cell. $\boldsymbol{D}$, Summary of cannabinoid effects on SPG cell activity in absence and presence of synaptic blockers. $\boldsymbol{E}$, Original recording illustrates depolarization of an $\mathrm{nPG}$ cell following bath application of AM251. sEPSPs were abolished following bath application of synaptic blockers (syn. blo.).

nPG cells. sPG cells generated firing patterns that were clearly distinct from those of ET cells (Hayar et al., 2004b, 2005; Ennis et al., 2007). sPG cells had an average $V_{\mathrm{m}}$ of $-57.7 \pm 0.6 \mathrm{mV}(n=$ $49)$, an input resistance of $732.3 \pm 36.9 \mathrm{M} \Omega(n=49)$, and cell capacitance of $6-11 \mathrm{pF}$. nPG cells had a more negative membrane potential $(-69.9 \pm 2.8 \mathrm{mV}, n=12)$, a higher input resistance $(1065.1 \pm 192.3 \mathrm{M} \Omega, n=12)$ and cell capacitance of $4-8 \mathrm{pF}$.

We first tested whether a selective CB1R agonist regulated PG cells. sPG cells exhibited spiking with an average firing rate of $3.9 \pm 0.3 \mathrm{~Hz}(n=31)$. WIN $(10 \mu \mathrm{M})$ reversibly decreased the firing rate of sPG cells (control: $4.4 \pm 0.4 \mathrm{~Hz}$ vs in WIN: $3.2 \pm 0.4$ $\mathrm{Hz}, n=11, p=0.0001)$ and hyperpolarized $V_{\mathrm{m}}\left(\Delta V_{\mathrm{m}}=-1.4 \pm\right.$ $0.2 \mathrm{mV}, n=11, p=0.02$ ) (Fig. 1). Similarly, CB1R-selective agonist anandamide displayed inhibitory effects on firing rate of sPCs (control: $3.7 \pm 0.6 \mathrm{~Hz}$ vs in anandamide: $2.5 \pm 0.6 \mathrm{~Hz}, n=$ $7, p=0.008)$ and hyperpolarization of $V_{\mathrm{m}}\left(\Delta V_{\mathrm{m}}=1.8 \pm 0.3 \mathrm{mV}\right.$, $n=7, p=0.002$ ) (Fig. 1C). In contrast, CB1R antagonist AM251 reversibly increased sPG cell firing (control: $4.0 \pm 0.5 \mathrm{~Hz}$ vs in AM251: $5.2 \pm 0.6 \mathrm{~Hz}, n=7, p=0.01)$ and depolarized them $\left(\Delta V_{\mathrm{m}}=1.9 \pm 0.4 \mathrm{mV}, n=6, p=0.02\right)$ (Fig. $\left.1 B\right)$. nPG cells also responded with depolarization to $\mathrm{CB} 1 \mathrm{R}$ inactivation (Fig. $1 E$ ). AM251 $(10 \mu \mathrm{M})$ depolarized by $5.7 \pm 1.6 \mathrm{mV}(n=5 ; p=0.037$, Wilcoxon), whereas WIN (10 $\mu \mathrm{M})$ hyperpolarized $\mathrm{nPG}$ cells by $-2.3 \pm 0.6 \mathrm{mV}(n=5 ; p=0.043)$.

To determine whether the effects of eCBs on PG cells were mediated by CB1R, we tested whether AM251 blocked the WIN effects. In the presence of $10 \mu \mathrm{M}$ AM251, bath application of 10 $\mu \mathrm{M}$ WIN failed to induce a decrease in firing rate (in AM251: $4.3 \pm 0.6 \mathrm{~Hz}$ vs in AM251 plus WIN: $4.01 \pm 0.7 \mathrm{~Hz}, n=5, p=$ $0.66)$ or change in membrane potential $\left(\Delta V_{\mathrm{m}}=0.05 \pm 0.02 \mathrm{mV}\right.$, $n=5, p=0.90)$. These results implied that CB1R was involved in cannabinoid-mediated modulation of PG activity. 


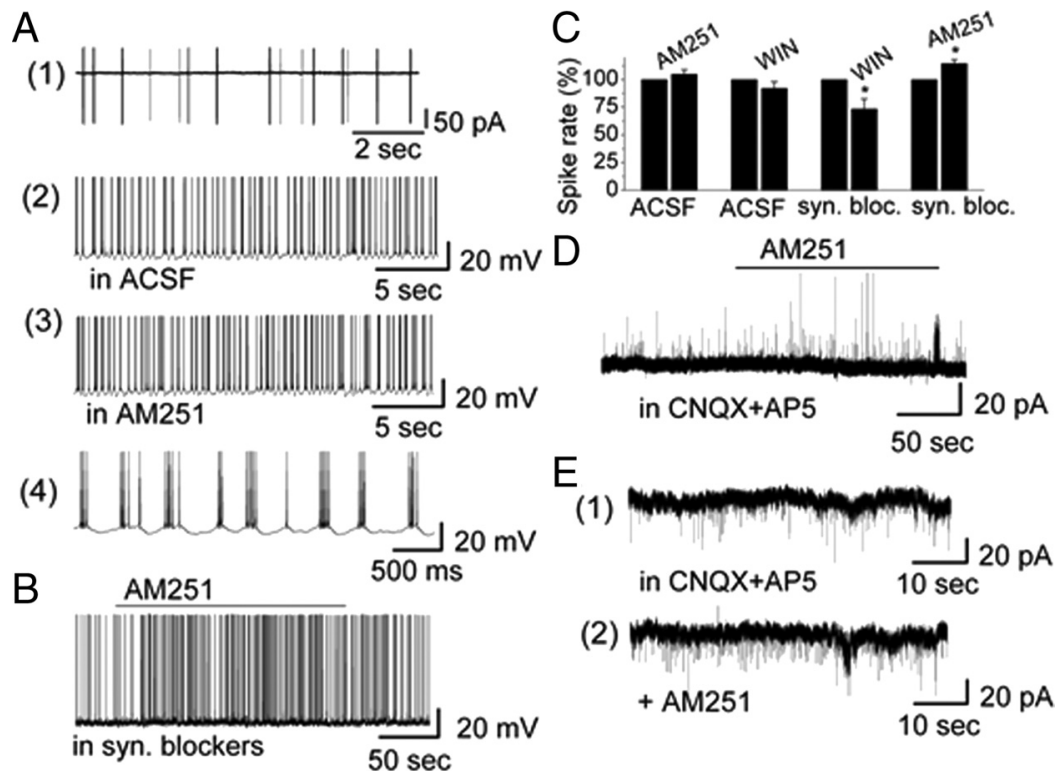

Figure 2. CB1R modified the activity of and synaptic transmission to ET cells. $A(1)$, Extracellular recording from an ET cell in cell-attached voltage-clamp mode to initially identify ET cells by their burst firing pattern. $A(2), A(3)$, The burst firing pattern of an ET cell recorded in absence and presence of $C B 1$ R antagonist AM251 in whole-cell current-clamp mode. The burst firing pattern of $\boldsymbol{A}(2)$ is shown at higher time resolution in $\boldsymbol{A ( 4 )}$. $\boldsymbol{B}, \mathrm{AM} 251$ increased the burst firing rate of an ET cell in the presence of synaptic blockers (10 $\mu \mathrm{m}$ CNQX $+50 \mu \mathrm{m}$ D-AP5 and $5 \mu \mathrm{m}$ gabazine). C, Group data illustrating the role of (B1R for burst firing of ET cells in absence and presence of synaptic blockers. Asterisks indicate significance level ( ${ }^{*} p<0.05$ ). D, AM251 induced an increase of sIPSCs in an ET cell in the presence of CNQX + D-AP5 with low-Cl ${ }^{-}$-based pipette solution. Holding potential is at $0 \mathrm{mV}$. IPSCs appeared as upward deflections. $\boldsymbol{E}$, AM251 induced an increase of sIPSCS in ET cell in the presence of CNQX + D-AP5 with high-Cl ${ }^{-}$-based pipette solution. Holding potential was at $-60 \mathrm{mV}$. sIPSCs appeared as downward deflections.

Hz vs in WIN: $4.71 \pm 1.23 \mathrm{~Hz}, n=6, p=$ $0.46 ; V_{\mathrm{m}}$ : control: $-52.8 \pm 1.08 \mathrm{mV}$ vs in WIN: $-53.20 \pm 0.93 \mathrm{mV}, n=6, p=0.60)$ (Fig. 2A). However, in synaptic blockers, CB1R drugs had a modest effect on ET cells. In this condition, AM251 slightly increased firing of ET cells (control: $5.46 \pm$ $0.73 \mathrm{~Hz}$ vs in AM251: $6.10 \pm 0.76 \mathrm{~Hz}, n=$ $9, p=0.002$ ) (Fig. $2 B$ ). We did not observe a significant membrane depolarization by AM251 (control: $-53.5 \pm 1.1 \mathrm{mV}$ vs in AM251: $-52.8 \pm 1.1 \mathrm{mV}, n=9, p=$ $0.18)$. In synaptic blockers, WIN slightly decreased firing of ET cells (control: $4.70 \pm 0.73 \mathrm{~Hz} \mathrm{mV}$ vs in WIN: $3.52 \pm 0.89$ $\mathrm{Hz}, n=5, p=0.043)$ but failed to change $V_{\mathrm{m}}$ (control: $-53.1 \pm 1.1 \mathrm{mV}$ vs in WIN: $-53.9 \pm 1.1 \mathrm{mV}, n=5, p=0.10)$. The effects of CB1R drugs in synaptic blockers indicate that CB1R mediated a direct effect on ET cells (Fig. 2C).

$\mathrm{CB} 1 \mathrm{R}$ regulated activity of $\mathrm{PG}$ cells and might modify GABA release and transmission to ET cells. This hypothesis was supported by our observation that AM251 increased sIPSC frequency and WIN decreased sIPSC frequency in ET cells. The effect of AM251 on sIPSCs was tested with both low- $\mathrm{Cl}^{-}$and high- $\mathrm{Cl}^{-}$-based pipette solution. In whole-cell voltageclamp recording mode with low- $\mathrm{Cl}^{-}$pi-

To further determine whether the actions of cannabinoids on PG cells were mediated through CB1R expressed by PG cells, we tested the effects of CB1R activation/inactivation on PG cells in the presence of ionotropic glutamate and $\mathrm{GABA}_{\mathrm{A}}$ receptor blockers (synaptic blockers; CNQX, $10 \mu \mathrm{M}$; APV, $50 \mu \mathrm{M}$; gabazine, 5 $\mu \mathrm{M})$. The effects of WIN $(10 \mu \mathrm{M})$ and AM251 $(10 \mu \mathrm{M})$ on firing and membrane potential of PG cells persisted in the presence of synaptic blockers (Fig. 1D). In synaptic blockers, AM251 increased reversibly the firing rate of sPG cells from $4.5 \pm 0.9 \mathrm{~Hz}$ to $5.9 \pm 0.9 \mathrm{~Hz}(n=5, p=0.01)$ and depolarized $V_{\mathrm{m}}\left(\Delta V_{\mathrm{m}}=1.6 \pm\right.$ $0.2 \mathrm{mV}, n=5, p=0.02$ ) (Fig. $1 D$ ). In contrast, WIN reduced the firing rate of sPG cells in synaptic blockers from $4.2 \pm 0.6 \mathrm{~Hz}$ to $3.0 \pm 0.5 \mathrm{~Hz}(n=6, p=0.003)$ and hyperpolarized $V_{\mathrm{m}}\left(\Delta V_{\mathrm{m}}=\right.$ $-0.9 \pm 0.2 \mathrm{mV}, n=6, p=0.02$ ) (Fig. $1 D$ ). The effects of CB1R drugs on sPG cells in synaptic blockers were not significantly different from those without blockers ( $p>0.05$ determined by ANOVA and Bonferroni post hoc analysis). For nPG cells, AM251 (10 $\mu \mathrm{M})$ depolarized cells in synaptic blockers by $5.0 \pm 1.0 \mathrm{mV}(n=5 ; p=$ $0.043)$, and WIN $(10 \mu \mathrm{M})$ hyperpolarized cells by $-1.9 \pm 0.4 \mathrm{mV}$ $(n=5 ; p=0.042)$. These results indicated that CB1R directly regulated membrane properties of both PG cell subtypes.

\section{Cannabinoids regulate activity of and synaptic transmission to ET cells}

CB1R-regulated activity of PG cells may modulate transmitter release and synaptic transmission to ET cells. We tested the effects of CB1R drugs on the activity of ET cells $(n=39)$. Neither agonist AM251 $(10 \mu \mathrm{M})$ nor antagonist WIN $(10 \mu \mathrm{M})$ significantly influenced overall firing frequency and membrane potential of ET cells (spiking: control: $5.36 \pm 1.28 \mathrm{~Hz}$ vs in AM251: $5.49 \pm 1.31$ $\mathrm{Hz}, n=5, p=0.89 ; V_{\mathrm{m}}$ : control: $-52.7 \pm 1.02 \mathrm{mV}$ vs in AM251: $-52.0 \pm 1.16 \mathrm{mV}, n=5, p=0.26$; spiking: control: $4.97 \pm 1.25$ pette solution and holding potential at $0 \mathrm{mV}$, AM251 increased the frequency of sIPSCs in blockers of ionotropic glutamate receptors (CNQX, D-AP5) (Fig. 2D). In this condition, sIPSCs were upward and exhibited some rundown. Thus, a high- $\mathrm{Cl}^{-}$pipette solution was used in the subsequent experiments. In blockers of ionotropic glutamate receptors, AM251 evoked an increase in sIPSC frequency from $1.08 \pm 0.27 \mathrm{~Hz}$ to $1.67 \pm 0.33 \mathrm{~Hz}(n=5$, $p=0.033$ ) associated with an increase of current amplitude from $22.8 \pm 4.3 \mathrm{pA}(\mathrm{CNQX}, \mathrm{D}-\mathrm{AP} 5)$ to $26.5 \pm 4.8 \mathrm{pA}(n=5, p=$ 0.042 ) (Fig. $2 E$ ). sIPSCs were completely eliminated by gabazine (sIPSC frequency: $<0.01 \mathrm{~Hz}, n=5, p=0.0001$ ), indicating that currents were mediated by $\mathrm{GABA}_{\mathrm{A}}$ receptors. The results indicated that AM251 directly activated PG cells and enhanced their GABA release.

\section{CB1R-mediated depolarization-induced suppression of inhibition}

DSI has not been demonstrated in the olfactory system. Based on our above results, we hypothesized that DSI might be present in the glomerular layer of MOB. First, we tested whether DSI can be induced by depolarization of the postsynaptic neuron, ET cells. With a $5 \mathrm{~s}$ depolarizing voltage step from a holding potential of -60 to $0 \mathrm{mV}$, DSI was clearly visible in ET cells as a decrease in the amplitude and frequency of sIPSCs (Fig. $3 A$ ). Immediately after a single depolarizing step, the sIPSC area was suppressed by $40.3 \pm$ $9.0 \%$ of control and then gradually recovered $(n=7 ; p<0.05)$ (Fig. $3 E$ ). To determine a possible functional role of DSI in glomeruli, we mimicked spontaneous rhythmic bursting of ET cells by applying a train of depolarizing steps. A train of depolarizing steps resulted in a transient reduction in sIPSC area (20 steps, $0.75 \mathrm{~Hz}$ ) (Fig. 3B). Suppression of sIPSCs reached a maximum of $59.5 \pm 5.3 \%$ within $7 \mathrm{~s}$ after the train of depolarizing steps with 
significant suppression lasting $25 \mathrm{~s}(n=$ $12 ; p<0.05$ ) (Fig. $3 B, F$ ). In the presence of AM251, DSI was completely eliminated ( $n=10)$ suggesting that DSI was mediated by CB1R (Fig. 3C,F). The bursting frequency of ET cells ranged from 0.5 to $6.5 \mathrm{~Hz}$ with a mean frequency of 2.7 bursts/s (Hayar et al., 2004a). In addition, the sustained depolarization during a burst is much lower than $0 \mathrm{mV}$ which is only transiently reached during action potentials. Therefore, we used a train of depolarizing steps to $-30 \mathrm{mV}$ at $2 \mathrm{~Hz}$ to test whether ET cell bursting can evoke DSI. Depolarizing voltage pulses at $2 \mathrm{~Hz}$ (20 steps, pulse duration: $250 \mathrm{~ms}$ ) evoked a reduction of sIPSCs in ET cells that was similar to the result obtained with voltage steps at $0.75 \mathrm{~Hz}$ to $0 \mathrm{mV}$. The maximal suppression at $2 \mathrm{~Hz}$ was $56.4 \pm 7.9 \%(n=7)$. Trains of depolarizing voltage steps evoked suppression of inhibition (DSI), suggesting that spontaneous rhythmic bursting of ET cells triggers the release of eCBs from ET cells. The data suggest that eCBs function as retrograde messengers to reduce GABA release from PG cells which in turn, regulates the activity of PG cell synaptic targets such as ET cells.

\section{Discussion}

We present electrophysiological evidence that the eCB system plays a functional role in regulating neuronal activity and signaling in MOB glomeruli. We found evidence for the existence of CB1R-mediated retrograde signaling among glomerular neurons in the form of DSI. Our results support the idea that eCBs released from ET cells function as retrograde messengers to control the excitability of presynaptic neurons, i.e., PG cells, and to regulate their transmitter release.

Our electrophysiological evidence is consistent with immunohistochemical studies that show CB1R is present in the glomerular layer (Moldrich and Wenger, 2000). We added new evidence that CB1R is expressed by PG cells since a CB1R agonist/antagonist directly regulated PG cell activity. Bursting is intrinsic to ET cells and mediated by several ET cell intrinsic conductances (Liu and Shipley, 2008). In the presence of synaptic blockers, a CB1R agonist/antagonist regulated the activity of ET cells. The results suggest that CB1R is expressed in ET cells and may participate in modulating ET cell activity. However, we did not observe a change in ET cell activity as a result of activation or blockade of CB1R in the absence of synaptic blockers. We hypothesize that the direct excitatory effect of a CB1R antagonist on ET cells is opposed by increased GABAergic synaptic input from PG cells onto ET cells, i.e., the enhanced GABA release from PG cells triggered by a CB1R antagonist may dominate and mask the CB1R antagonistevoked direct excitation of ET cells.

In other brain systems, eCBs are synthesized and released from neuronal cell bodies as a result of cellular excitation
(Kano et al., 2009). One potential source of eCBs in the MOB is neurons that synapse onto presynaptic cells, i.e., PG cells, and receive feedback synaptic inputs. ET cells possess these characteristics, and could be a potential eCB source in the MOB. This hypothesis was supported by our observation of DSI in ET cells. ET cells displayed DSI depending on voltage step duration and step number. With step duration of $1 \mathrm{~s}$, we did not observe clear DSI in ET cells (data not shown). However, when the step duration was increased to $5 \mathrm{~s}$, transient DSI was evoked. A train of depolarizing voltage steps $(>3)$ strengthened the inhibition of sIPSCs, suggesting that excitation of ET cells in the form of rhythmic bursting triggers the release of eCBs and regulates glomerular activity. Bursting of neurons may modulate eCB release not only in the MOB but also in other brain systems.

Since ET cells receive monosynaptic sensory input, the inhibitory effect of CB1R on PG cells by eCBs reduces inhibitory input to ET cells and could enhance ET cell sensitivity to weak sensory inputs by depolarizing the membrane potential closer to spike threshold. eCBs released by ET cells inhibit PG cells, reduce their GABA release and, in turn, could modify the firing pattern of ET cells and could potentially also reduce inhibition of mitral cells and presynaptic olfactory nerve terminals. Activation of CB1R on PG cells may thus increase the overall sensitivity of the glomerulus to sensory inputs. 


\section{References}

Alger BE (2002) Retrograde signaling in the regulation of synaptic transmission: focus on endocannabinoids. Prog Neurobiol 68:247-286.

Allen Institute for Brain Science (2009) Allen mouse brain atlas [Online]. Seattle. http://mouse.brain-map.org.

Aroniadou-Anderjaska V, Zhou FM, Priest CA, Ennis M, Shipley MT (2000) Tonic and synaptically evoked presynaptic inhibition of sensory input to the rat olfactory bulb via GABA(B) heteroreceptors. J Neurophysiol 84:1194-1203.

Aungst JL, Heyward PM, Puche AC, Karnup SV, Hayar A, Szabo G, Shipley MT (2003) Centre-surround inhibition among olfactory bulb glomeruli. Nature 426:623-629.

Ennis, M, Hamilton, KA, and Hayar A (2007) Neurochemistry of the main olfactory system. In: Handbook of neurochemistry and molecular neurobiology (Lajtha A, editor-in-chief), vol: Sensory neurochemistry (Johnson DA, ed), pp 137-204. Springer: Heidelberg.

Fortin DA, Trettel J, Levine ES (2004) Brief trains of action potentials enhance pyramidal neuron excitability via endocannabinoid-mediated suppression of inhibition. J Neurophysiol 92:2105-2112.

Hayar A, Karnup S, Shipley MT, Ennis M (2004a) Olfactory bulb glomeruli: external tufted cells intrinsically burst at theta frequency and are entrained by patterned olfactory input. J Neurosci 24:1190-1199.

Hayar A, Karnup S, Ennis M, Shipley MT (2004b) External tufted cells: a major excitatory element that coordinates glomerular activity. J Neurosci 24:6676-6685.

Hayar A, Shipley MT, Ennis M (2005) Olfactory bulb external tufted cells are synchronized by multiple intraglomerular mechanisms. J Neurosci 25:8197-8208.

Heinbockel T, Heyward P, Conquet F, Ennis M (2004) Regulation of main olfactory bulb mitral cell excitability by metabotropic glutamate receptor mGluR1. J Neurophysiol 92:3085-3096.
Herkenham M, Lynn AB, Johnson MR, Melvin LS, de Costa BR, Rice KC (1991) Characterization and localization of cannabinoid receptors in rat brain: a quantitative in vitro autoradiographic study. J Neurosci 11:563-583.

Kano M, Ohno-Shosaku T, Hashimotodani Y, Uchigashima M, Watanabe M (2009) Endocannabinoid-mediated control of synaptic transmission. Physiol Rev 89:309-380.

Kiyokage E, Pan YZ, Shao Z, Kobayashi K, Szabo G, Yanagawa Y, Obata K, Okano H, Toida K, Puche AC, Shipley MT (2010) Molecular identity of periglomerular and short axon cells. J Neurosci 30:1185-1196.

Liu S, Shipley MT (2008) Multiple conductances cooperatively regulate spontaneous bursting in mouse olfactory bulb external tufted cells. J Neurosci 28:1625-1639.

Moldrich G, Wenger T (2000) Localization of the CB1 cannabinoid receptor in the rat brain. An immunohistochemical study. Peptides 21:1735-1742.

Murphy GJ, Darcy DP, Isaacson JS (2005) Intraglomerular inhibition: Signaling mechanisms of an olfactory microcircuit. Nat Neurosci $8: 354-364$.

Okamoto Y, Wang J, Morishita J, Ueda N (2007) Biosynthetic pathways of the endocannabinoid anandamide. Chem Biodivers 4:1842-1857.

Pettit DA, Harrison MP, Olson JM, Spencer RF, Cabral GA (1998) Immunohistochemical localization of the neural cannabinoid receptor in rat brain. J Neurosci Res 51:391-402.

Piomelli D (2003) The molecular logic of endocannabinoid signaling. Nat Rev Neurosci 4:873-884.

Shao Z, Puche AC, Kiyokage E, Szabo G, Shipley MT (2009) Two GABAergic intraglomerular circuits differentially regulate tonic and phasic presynaptic inhibition of olfactory nerve terminals. J Neurophysiol 101:1988-2001.

Tsou K, Brown S, Sañudo-Peña MC, Mackie K, Walker JM (1998) Immunohistochemical distribution of cannabinoid CB1 receptors in the rat central nervous system. Neuroscience 83:393-411. 